\title{
Haematological Parameters in Pregnant Women Attended Antenatal Care at Sabratha Teaching Hospital in Northwest, Libya
}

\author{
Azab Elsayed Azab ${ }^{1, ~ *, ~ M o h a m e d ~ O m a r ~ A l b a s h a ~}{ }^{1}$, Sara Yosef Elhemady ${ }^{2}$ \\ ${ }^{1}$ Department of Zoology, Faculty of Science, Alejelat Zawia University, Alejelat, Libya \\ ${ }^{2}$ Department of Medical Engineering, School of Applied and Engineering Sciences, Academy of Graduate Studies, Tripoli, Libya
}

Email address:

azabelsaied@yahoo.com (A. E. Azab)

*Corresponding author

\section{To cite this article:}

Azab Elsayed Azab, Mohamed Omar Albasha, Sara Yosef Elhemady. Haematological Parameters in Pregnant Women Attended Antenatal Care at Sabratha Teaching Hospital in Northwest, Libya. American Journal of Laboratory Medicine. Vol. 2, No. 4, 2017 , pp. 60-68. doi: 10.11648/j.ajlm.20170204.14

Received: February 18, 2017; Accepted: March 10, 2017; Published: October 23, 2017

\begin{abstract}
The aim of this study was to evaluate the values of hematological parameters at different trimesters of pregnancy in pregnant women who attended antenatal care at Sabratha Teaching Hospital, Northwest Libya. This cross-sectional survey included consecutive pregnant women who attended the obstetrical department in Sabratha Teaching Hospital for prenatal booking. This study was carried out over period of 6 month from April 2016 to September 2016. The study involved 120 pregnant women as the study group and 40 non-pregnant women as control. The study pregnant women were between the ages of 18 to 45 years. $5 \mathrm{ml}$ of venous blood samples were taken from each pregnant woman in $\mathrm{K}_{3}$-EDTA tubes for the haematological examinations. The analysis of haematological indices was done using automated hematological analyzer. The obtained results showed that the mean age of pregnant women was 30 years $\pm 5.8 \mathrm{SD}, 48.4 \%$ of pregnant women were between 21-30 years old, 40.8\% were at age between 31-40 years. The most prevalent blood group in pregnant women was group $\mathrm{O}, 47.5 \%$; followed by blood group $\mathrm{A}, 28.3 \%$; blood group $\mathrm{B}, 17.5 \%$ and blood group $\mathrm{AB}, 6.7 \% .15 .8 \%$ of the pregnant women were observed to lack $\mathrm{Rh}$ antigen in their blood. Highly significance decrease in $\mathrm{Hb}, \mathrm{Hct}, \mathrm{MCH}, \mathrm{MCHC}$, lymphocytes\%, RBCs and blood platelets count and significant decrease in MCV as compared with non pregnant women. On the other hand, highly significance increased in WBCs count, and neutrophils \% of pregnant women compared with non pregnant women. A progressive decline in $\mathrm{Hb}$ concentration and haematocrite values from the first to third trimester was observed. The mean corpuscular volume was significantly decreased in the second trimester. The values of $\mathrm{MCH}$ showed highly significant decrease in the second and third trimester, and MCHC decreased significantly in the first trimester. WBC count and neutrophils \% showed highly significant increase from the first to the third trimester. Lymphocytes \% were highly significant decreased from the first to the third trimester. Mixed percentage of leukocytes (eosinophil, basophil and monocytes) decreased significantly in the third trimester. Platelets count exhibited a highly significant decrease in the second and third trimesters, and a significantly decrease in the first trimester. It can be concluded that a significant changes in the haematological parameters at different trimesters of pregnancy in pregnant women. So it is essential to monitor and manage these parameters during pregnancy.
\end{abstract}

Keywords: Haematological Changes, Pregnant Women, Trimesters of Pregnancy, Blood Groups

\section{Introduction}

Pregnancy is the time during which one or more offspring develops inside a woman's womb. In a pregnancy, there can be multiple gestations, as in the case of twins or triplets. Childbirth usually occurs approximately 38 weeks after conception. In case of women who have a menstrual cycle length of 4 weeks, this is approximately 40 weeks from the last normal menstrual [1]. Pregnancy is influenced by many factors, some of 
which include culture, environment, socioeconomic status, and access to medical care [2]. Pregnancy is a state characterized by many physiological hematological changes, which may appear to be pathological in the nonpregnant state [3]. The hematologic system undergoes a series of adaptive changes in preparation for fetal hematopoiesis and wellbeing while also serving as a cushion against expected blood loss at delivery. These changes range from the increased plasma volume and red blood cell mass, leucocytosis and adaptive immunological changes in the relative hypercoagulable state of pregnancy and tend to commence as early as the $6^{\text {th }}$ week of gestation with a resolution by the $6^{\text {th }}$ week postpartum [4].

Anemia is the most common hematological problem in pregnancy, followed by thrombocytopenia. Leukocytosis is almost always associated with pregnancy [5]. In 2011, $29 \%$ (496 million) of non-pregnant women and 38\% (32.4 million) of pregnant women aged 15-49 years were anaemic [6]. About $20 \%$ of maternal deaths occur due to anaemia [7].

The platelets count is slightly lower in pregnant than in non pregnant women [8]. Most studies report an approximate $10 \%$ lower platelets level at term compared with at pre-pregnancy $[9,10]$.

Previous studies have reported that pregnancy is usually accompanied by leukocytosis, but the full sequential changes of the various cell types responsible for this observed leukocytosis have not been clearly determined in all geographical locations and physiological conditions [5, 11]. Few epidemiological studies on the haematological changes in pregnant women were done in a different part of Libya. Therefore, the aim of this study is to evaluate the values of major hematological parameters [(RBCs, WBC, and PLTs count, $\mathrm{Hb}$ concentration, hematocrite value (Hct), mean cell volume (MCV), mean corpuscular hemoglobin $(\mathrm{MCH})$, and mean corpuscular hemoglobin concentration (MCHC)] at different trimesters of pregnancy in pregnant women who attended antenatal care at Sabratha Teaching Hospital, Northwest Libya.

\section{Subjects and Methods}

This cross-sectional survey included consecutive pregnant women who attended the obstetrical department in Sabratha Teaching Hospital for prenatal booking. This study was carried out over period of 6 month from April 2016 to September 2016. The study involved 120 pregnant women as the study group and 40 non-pregnant women as control. The study pregnant women were between the ages of 18 to 45 years. They were provided select information about a current pregnancy, existence or non-existence of prenatal follow-ups. Pregnant woman age was recorded. Each woman was underwent a thorough medical interview and clinical examination and complete blood count. A battery of tests were followed: HCV, HBV, and HIV screening, thick and thin blood films to identify blood parasites. $5 \mathrm{ml}$ of venous blood specimens were take from each pregnant woman in $\mathrm{K}_{3}$-EDTA tubes for the haematological examinations.

\subsection{Determination of Haematological Parameters}

Red blood cells (RBCs) count, haemoglobin concentration $(\mathrm{Hb})$, haematocrite value $(\mathrm{Hct})$, blood indices [Mean corpuscular volume (MCV), mean corpuscular haemoglobin $(\mathrm{MCH})$, mean corpuscular haemoglobin concentration (MCHC), white blood cells (WBCs) count, differential count of leucocytes, and blood platelets count were determine using an automated haematology analyzer sysmax (KX 21) machine in Sabratha Teaching Hospital laboratory.

\subsection{Determination of $A B O$ and Rh Blood Groups}

Blood group determination was done with forward and reverse cell typing using test tube agglutination method. Antiglobulin technique was applied to confirm $\mathrm{Rh}$ negativity [12].

\subsection{Statistical Analysis}

Results were expressed as mean \pm SE. Data were analyzed by one way ANOVA (SPSS for windows, USA). The difference between means $\pm \mathrm{SE}$ was test at $\mathrm{P}<0.05$ using $\mathrm{T}$ - test. In all statistical tests, the probability level of $\mathrm{P}$ $<0.05$ was considered significant.

\section{Results}

\subsection{Distribution of Pregnant Women According to Age Group}

This cross-sectional survey was included consecutive pregnant women who were attended the obstetrical department in Sabratha Teaching Hospital for prenatal booking. This study was carried out over period of 6 month from April 2016 to September 2016. 120 pregnant women were included. The mean age was 30 years $\pm 5.8 \mathrm{SD}$ (ranged from $18-45$ years). There were 58 pregnant women (48.4\%) between 21-30 years old, 49 (40.8\%) were with age between $31-40$ years, $07(5.8 \%)$ were with age $>40$ years, and $06(5 \%)$ were with age $<20$ years (Table 1$)$.

Table 1. Distribution of pregnant women according to age group.

\begin{tabular}{lll}
\hline Age group (Years) & Frequency & Percentage (\%) \\
\hline$<20$ & 06 & 5 \\
$21-30$ & 58 & 48.4 \\
$31-40$ & 49 & 40.8 \\
$>40$ & 07 & 5.8 \\
\hline
\end{tabular}

\subsection{Frequency of Pregnant Women According to Number of Pregnancies}

Most of pregnant women were among those who have their first pregnancy (primigravida) when their percent reach $33 \%$ (39 pregnant women) then these who had 2 children $25 \%$ (30 pregnant women), then these who had 3 children 
$22 \%$ (26 pregnant women), and for $21 \%$ (25 pregnant women) multipara (4-8 children). (Table 2).

Table 2. Frequency of pregnant women according to number of pregnancies.

\begin{tabular}{lll}
\hline Number of pregnancies & Frequency & Percentage (\%) \\
\hline Primigravid (1) & 39 & 33 \\
2 & 30 & 25 \\
3 & 26 & 22 \\
MultiPara (4-8) & 25 & 21 \\
\hline
\end{tabular}

\subsection{ABO and Rhesus (D) Blood Group Distribution Among Pregnant Women}

Group $\mathrm{O}$ was found to be the most abundant blood group, 47.5\% (57 pregnant women); followed by blood group A, 28.3\% (34 pregnant women); blood group B, $17.5 \%$ (21 pregnant women) and blood group $\mathrm{AB}, 6.7 \%$ (08 pregnant women). Out of the total pregnant women screened $15.8 \%$ (19 pregnant women) of them lack $\mathrm{Rh}$ antigen in their blood (Table 3 ). The negativity rate for $\mathrm{Rh}$ antigen was higher in $\mathrm{O} \& \mathrm{~A}$ blood group (5.83\%), followed by B blood group (3.30\%), and AB blood group $(0.80 \%)$ (Table 3$)$.

Table 3. ABO and Rhesus (D) blood group distribution among pregnant women.

\begin{tabular}{llll}
\hline Blood group & Total No. $(\%)$ & Rh $(\mathbf{D})+\mathbf{v e}(\%)$ & Rh (D) -ve (\%) \\
\hline A & $34(28.3)$ & $27(22.50)$ & $07(5.83)$ \\
B & $21(17.5)$ & $17(14.20)$ & $04(3.30)$ \\
AB & $08(6.7)$ & $07(5.83)$ & $01(0.80)$ \\
O & $57(47.5)$ & $50(41.70)$ & $07(5.83)$ \\
Total & 120 & $101(84.2)$ & $19(15.8)$ \\
\hline
\end{tabular}

\subsection{Distribution of Pregnant Women According to Employment Status}

In terms of employment, $67.5 \%(81 / 120)$ were employed, and $32.5 \%(39 / 120)$ were housewives. In terms of type of employment, $35.8 \%(43 / 120)$ were teachers, $15 \%(18 / 120)$ worked in hospitals, $8.3 \%(10 / 120)$ were office workers, 5.8 $(07 / 120)$ were university staff members and $2.5 \%(03 / 120)$ were Engineers (Table 4).

Table 4. Distribution of pregnant women according to employment status.

\begin{tabular}{lll}
\hline Employment status & Frequency & Percentage (\%) \\
\hline Office workers & 10 & 8.3 \\
University staff members & 07 & 5.8 \\
Worked in hospitals & 18 & 15 \\
Housewife & 39 & 32.5 \\
Teachers & 43 & 35.6 \\
Engineers & 03 & 2.5 \\
\hline
\end{tabular}

\subsection{Haematological Profile of Non Pregnant Women and Pregnant Women}

The results of this study showed in pregnant women highly significance decrease in $\mathrm{Hb}$, Hct, $\mathrm{MCH}, \mathrm{MCHC}$, lymphocytes\%, RBCs and blood platelets count and significant decrease in MCV compared with non pregnant women (Table 5). On the other hand, highly significance increased in WBCs count, and neutrophils \% of pregnant women compared with non pregnant women (Table 5).

Table 5. Haematological profile of non pregnant women and pregnant women.

\begin{tabular}{|c|c|c|}
\hline Groups & Non Pregnant (Controls) & Pregnant Women \\
\hline Parameters & Mean \pm SE & Mean \pm SE \\
\hline $\operatorname{RBCs}\left(\times 10^{6} / \mu \mathrm{l}\right)$ & $4.45 \pm 0.06$ & $4.11 \pm 0.05^{* *}$ \\
\hline $\mathrm{Hb}(\mathrm{g} / \mathrm{dl})$ & $12.84 \pm 0.10$ & $10.91 \pm 0.13^{* *}$ \\
\hline $\mathrm{Hct} \%$ & $37.62 \pm 0.60$ & $33.56 \pm 0.48^{* *}$ \\
\hline $\operatorname{MCV}\left(\mu^{3}\right)$ & $84.74 \pm 1.25$ & $82.10 \pm 1.01$ \\
\hline $\mathrm{MCH}(\mathrm{pg})$ & $28.96 \pm 0.31$ & $26.85 \pm 0.37^{* *}$ \\
\hline $\operatorname{MCHC}(\mathrm{g} / \mathrm{dl})$ & $34.46 \pm 0.64$ & $32.82 \pm 0.34^{*}$ \\
\hline WBCs $\left(\times 10^{3} / \mu \mathrm{l}\right)$ & $6.64 \pm 0.36$ & $8.26 \pm 0.19^{* *}$ \\
\hline Neutrophils \% & $50.08 \pm 1.20$ & $66.40 \pm 0.77^{* *}$ \\
\hline Lymphocytes \% & $37.11 \pm 2.20$ & $26.45 \pm 0.66^{* *}$ \\
\hline Mixed \% & $7.91 \pm 0.30$ & $7.25 \pm 0.16^{*}$ \\
\hline Platelets $\left(\mathrm{X} 10^{3} / \mu \mathrm{L}\right)$ & $264.1 \pm 8.00$ & $227.1 \pm 4.6^{* *}$ \\
\hline
\end{tabular}

(*) significant difference compared to non pregnant women (controls) group $(\mathrm{P}<0.05)$. $(* *)$ highly significant difference compared to non pregnant women (controls) group (P $<0.01)$.

\subsection{Haematological Profile of Non Pregnant Women and Pregnant Women Based on Trimesters}

The data shown in table (6) and figure (1) indicated a highly significant decrease in RBCs counts at the first $(4.09 \pm 0.08) \times 10^{6}$ cell $/ \mu 1$, and third $(4.03 \pm 0.08) \times 10^{6}$ cell $/ \mu 1$ trimesters, and a significant decreased at the second trimester $(4.22 \pm 0.10) \times 10^{6}$ cell $/ \mu \mathrm{l}$ compared to non pregnant women $(4.45 \pm 0.06) \times 10^{6} \mathrm{cell} / \mu \mathrm{l}$.

Highly significant decreased in hemoglobin content was found in the first, second and third trimester respectively $(11.27 \pm 019) \mathrm{g} / \mathrm{dl}, 10.84 \pm 0.23) \mathrm{g} / \mathrm{dl}$, and $(10.61 \pm 0.26)$ $\mathrm{g} / \mathrm{dl}$ compared to non pregnant women $(12.84 \pm 0.10) \mathrm{g} / \mathrm{dl}$ (Table 6 \& Figure 2).

Hematocrite values were highly significant decreased $(34.72 \pm 0.69 \%, 33.35 \pm 0.90 \%$ and $32.60 \pm 0.87 \%)$ in the first, second and third trimester respectively compared to non pregnant women $(37.62 \pm 0.60 \%)$ (Table $6 \&$ Figure 3).

Table 6. Haematological profile of non pregnant women and pregnant women based on trimesters.

\begin{tabular}{|c|c|c|c|c|}
\hline \multirow{3}{*}{ Parameters } & \multirow{2}{*}{$\begin{array}{l}\text { Non Pregnant } \\
\text { (Controls) }\end{array}$} & \multicolumn{3}{|c|}{ Pregnant Women (Trimesters) } \\
\hline & & First & Second & Third \\
\hline & Mean \pm SE & Mean \pm SE & Mean \pm SE & Mean \pm SE \\
\hline RBCs $\left(\times 10^{6} / \mu \mathrm{l}\right)$ & $4.45 \pm 0.06$ & $4.09 \pm 0.08 * *$ & $4.22 \pm 0.10^{*}$ & $4.03 \pm 0.08 * *$ \\
\hline $\mathrm{Hb}(\mathrm{g} / \mathrm{dl})$ & $12.84 \pm 0.10$ & $11.27 \pm 019 * *$ & $10.84 \pm 0.23 * *$ & $10.61 \pm 0.26^{* *}$ \\
\hline $\mathrm{Hct} \%$ & $37.62 \pm 0.60$ & $34.72 \pm 0.69 * *$ & $33.35 \pm 0.90 * *$ & $32.60 \pm 0.87 * *$ \\
\hline
\end{tabular}




\begin{tabular}{|c|c|c|c|c|}
\hline \multirow{3}{*}{ Parameters } & \multirow{2}{*}{$\begin{array}{l}\text { Non Pregnant } \\
\text { (Controls) }\end{array}$} & \multicolumn{3}{|c|}{ Pregnant Women (Trimesters) } \\
\hline & & First & Second & Third \\
\hline & Mean \pm SE & Mean \pm SE & Mean \pm SE & Mean \pm SE \\
\hline $\operatorname{MCV}\left(\mu^{3}\right)$ & $84.74 \pm 1.25$ & $85.27 \pm 1.22$ & $79.59 \pm 1.87^{*}$ & $81.45 \pm 1.97$ \\
\hline $\mathrm{MCH}(\mathrm{pg})$ & $28.96 \pm 0.31$ & $27.78 \pm 0.45$ & $26.09 \pm 0.68 * *$ & $26.67 \pm 0.72 * *$ \\
\hline MCHC (g/dl) & $34.46 \pm 0.64$ & $32.65 \pm 0.45^{*}$ & $33.03 \pm 0.75$ & $32.78 \pm 0.54$ \\
\hline WBCs $\left(\times 10^{3} / \mu 1\right)$ & $6.64 \pm 0.36$ & $8.39 \pm 0.36 * *$ & $7.69 \pm 0.31^{*}$ & $8.72 \pm 0.32 * *$ \\
\hline Neutrophils \% & $50.08 \pm 1.20$ & $65.27 \pm 1.56^{* *}$ & $66.47 \pm 1.32 * *$ & $67.46 \pm 1.07 * *$ \\
\hline Lymphocytes \% & $37.11 \pm 2.20$ & $27.73 \pm 1.38 * *$ & $26.10 \pm 1.12 * *$ & $25.53 \pm 0.85 * *$ \\
\hline Mixed \% & $7.91 \pm 0.30$ & $7.40 \pm 0.27$ & $7.36 \pm 0.28$ & $6.98 \pm 0.28^{*}$ \\
\hline Platelets $\left(\mathrm{X} 10^{3} / \mu \mathrm{L}\right)$ & $264.1 \pm 8.00$ & $241.7 \pm 7.4 *$ & $234.9 \pm 8.20 * *$ & $204.8 \pm 7.40 * *$ \\
\hline
\end{tabular}

$\left.\mathrm{n}=40,{ }^{*}\right)$ significant difference compared to non pregnant women (controls) group $(\mathrm{P}<0.05)$.

$(* *)$ highly significant difference compared to non pregnant women (controls) group $(\mathrm{P}<0.01)$

Significant decreased in mean corpuscular volume in the second trimester $(79.59 \pm 1.87 \mathrm{fl})$, and non significant changes $(85.27 \pm 1.22 \mathrm{fl}$, and $81.45 \pm 1.97 \mathrm{fl})$ in the first and third trimesters respectively compared to non pregnant women $(84.74 \pm 1.25 \mathrm{fl})$ (Table $6 \&$ Figure 4$)$.

The values of $\mathrm{MCH}$ were highly significant decreased $(26.09 \pm 0.68 \mathrm{pg}$, and $26.67 \pm 0.72 \mathrm{pg})$ in the second and third trimester respectively, and non significant changed in the first trimester $(27.78 \pm 0.45 \mathrm{pg})$ compared to non pregnant women $(28.96 \pm 0.31 \mathrm{pg})$ (Table $6 \&$ Figure 5).

$\mathrm{MCHC}$ of the pregnant women was a significantly decreased in the first trimester $(32.65 \pm 0.45 \mathrm{~g} / \mathrm{dl})$, and non significantly changes $(33.03 \pm 0.75 \mathrm{~g} / \mathrm{dl}),(32.78 \pm 0.54$ $\mathrm{g} / \mathrm{dl})$ in the second and third trimesters respectively as compared to non pregnant women $(34.46 \pm 0.64 \mathrm{~g} / \mathrm{dl})$ (Table 6 \& Figure 6).

The data recorded in table (6) and figure (7) indicated a highly significant increase in WBCs count at the first $(8.39 \pm 0.36) \times 10^{3}$ cell $/ \mu 1$, and third $(8.72 \pm 0.32) \times 10^{3}$ cell $/ \mu 1$ trimesters, and a significant at the second trimester $(7.69 \pm 0.31) \times 10^{3}$ cell $/ \mu 1$ when compared with non pregnant women $(6.64 \pm 0.36) \times 10^{3}$ cell $/ \mu 1$.

The data obtained are presented in table (6) and demonstrated by figure (8). It is apparent from the result, neutrophils \% were highly significant increased (65.27 \pm $1.56 \%),(66.47 \pm 1.32 \%),(67.46 \pm 1.07 \%)$ in the first, second, and third trimesters, respectively as compared with non pregnant women $(50.08 \pm 1.20 \%)$.

As shown in table (6) and figure (9) lymphocytes \% was highly significant decreased $(27.73 \pm 1.38 \%),(26.10 \pm$ $1.12 \%),(25.53 \pm 0.85 \%)$ in the first, second and third trimesters, respectively compared to non pregnant women $(37.11 \pm 2.20 \%)$.

Mixed percentage of leukocytes was decreased significantly in the third trimesters $(6.98 \pm 0.28 \%)$, and non significant changed $(7.40 \pm 0.27 \%),(7.36 \pm 0.28 \%)$ in the first and second trimesters when compared with non pregnant women $(7.91 \pm 0.30 \%)$ (Table 6 \& Figure 10).

Blood platelets count exhibited a highly significant decreases $\left(234.9 \pm 8.20 \times 10^{3}\right) \mathrm{cell} / \mu \mathrm{l},(204.8 \pm 7.40) \times 10^{3}$ cell $/ \mu \mathrm{l}$ in the second and third trimesters, respectively, and significant decreases in the first trimester $(241.7 \pm 7.4) \mathrm{x}$ $10^{3} \mathrm{cell} / \mu \mathrm{l}$ compared to non pregnant women $(264.1 \pm$
8.00) $\times 10^{3}$ cell/ $\mu 1$ as shown in table (6) and figure (11).

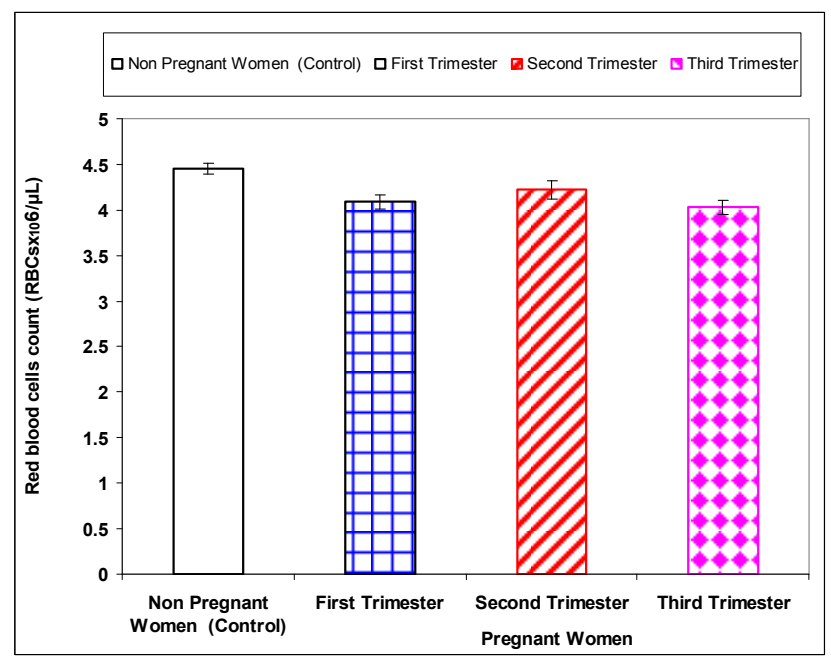

Figure 1. RBCs count in non pregnant and pregnant women at the first, second and third trimesters.

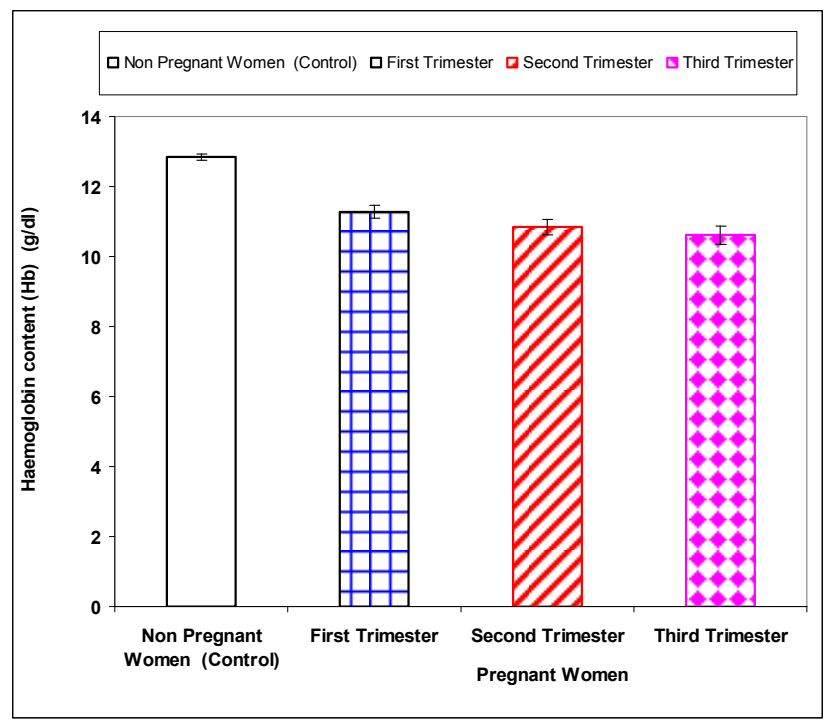

Figure 2. Hemoglobin content in non pregnant and pregnant women at the first, second and third trimesters. 


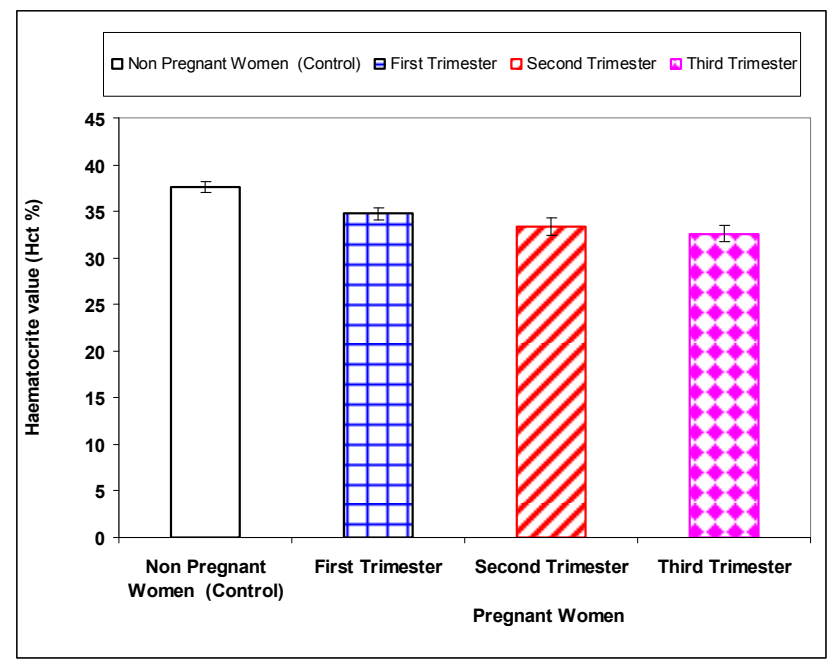

Figure 3. Haematocrite value in non pregnant and pregnant women at the first, second and third trimesters.

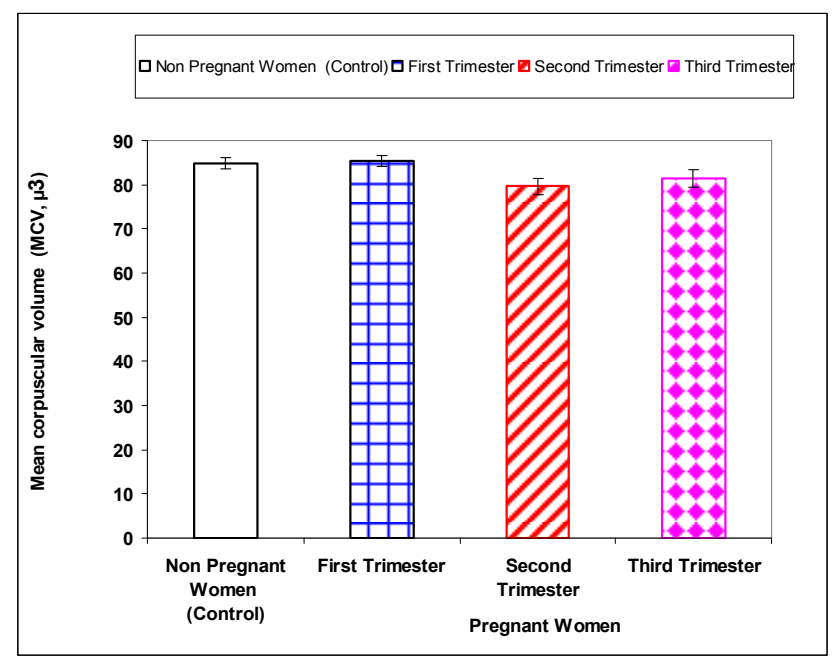

Figure 4. Mean corpuscular volume (MCV) in non pregnant and pregnant women at the first, second and third trimesters.

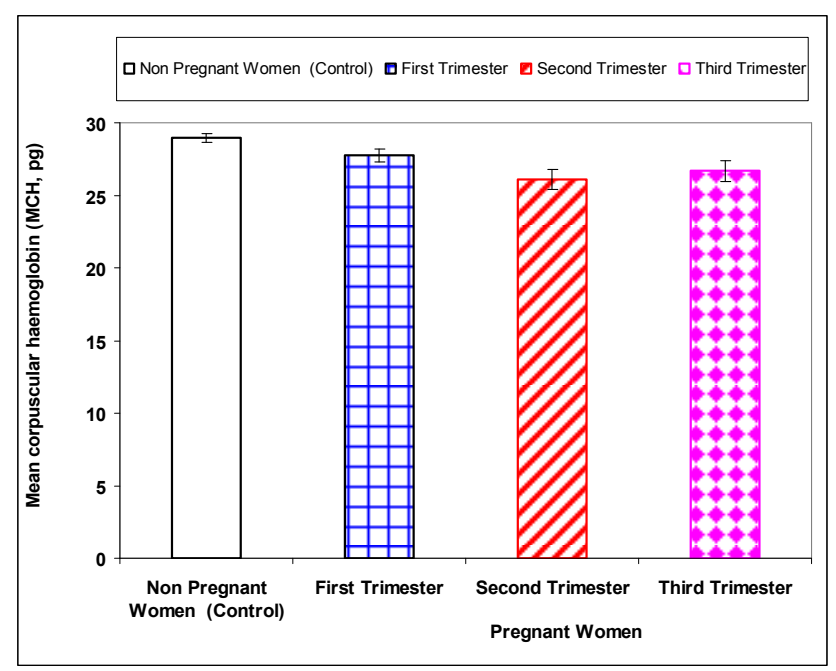

Figure 5. Mean corpuscular hemoglobin $(M C H)$ in non pregnant and pregnant women at the first, second and third trimesters.

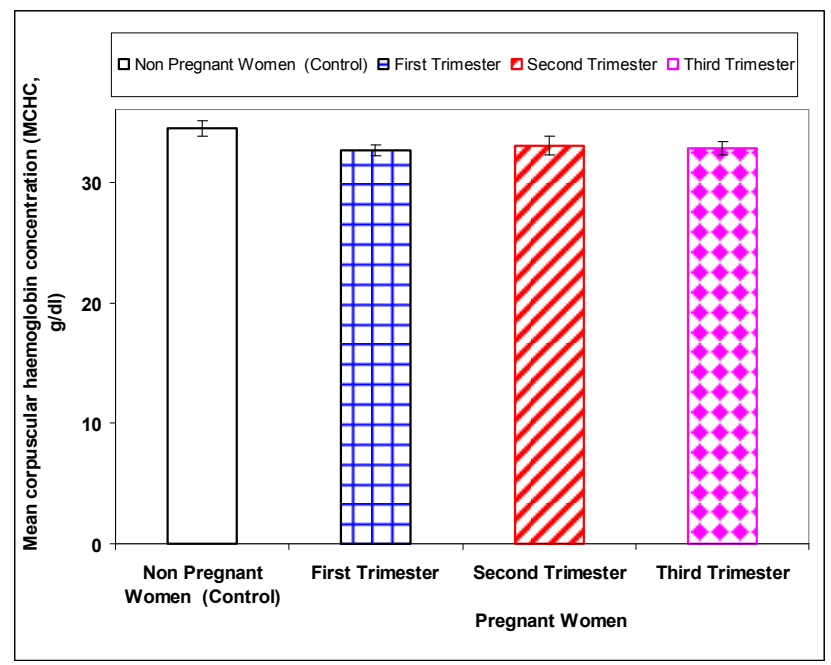

Figure 6. Mean corpuscular hemoglobin concentration (MCHC) in non pregnant and pregnant women at the first, second and third trimesters.

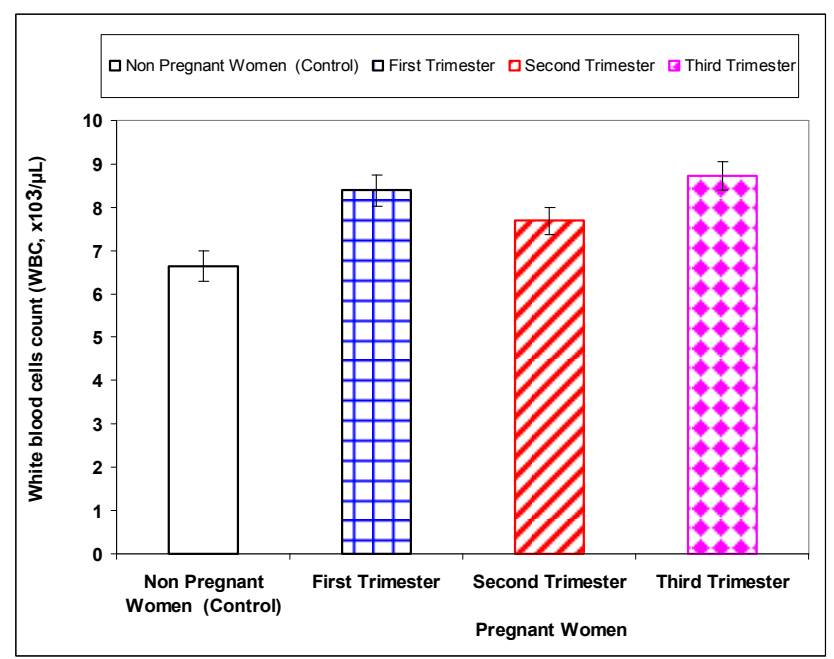

Figure 7. White blood cells (WBCS) count in non pregnant and pregnant women at the first, second and third trimesters.

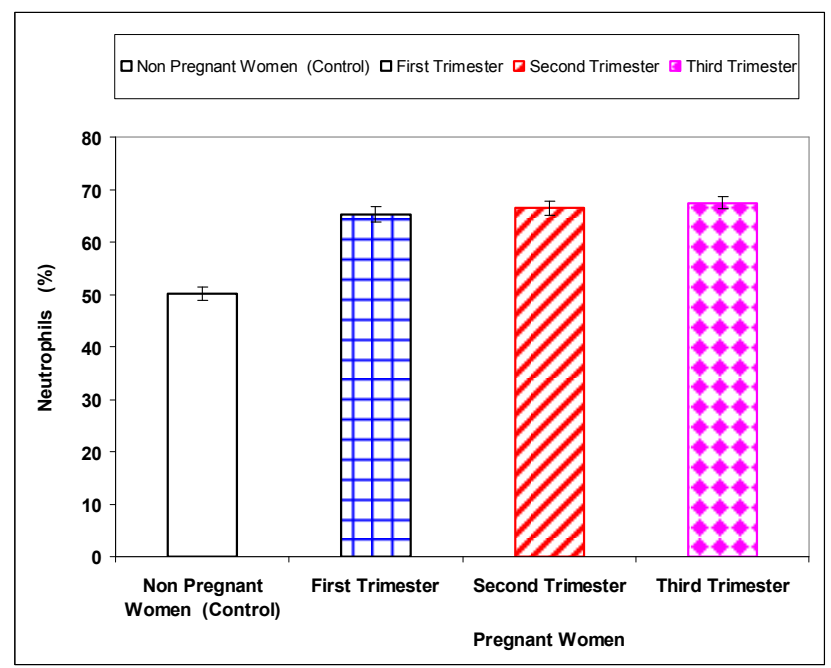

Figure 8. Neutrophils percentage (\%) in non pregnant and pregnant women at the first, second and third trimesters. 


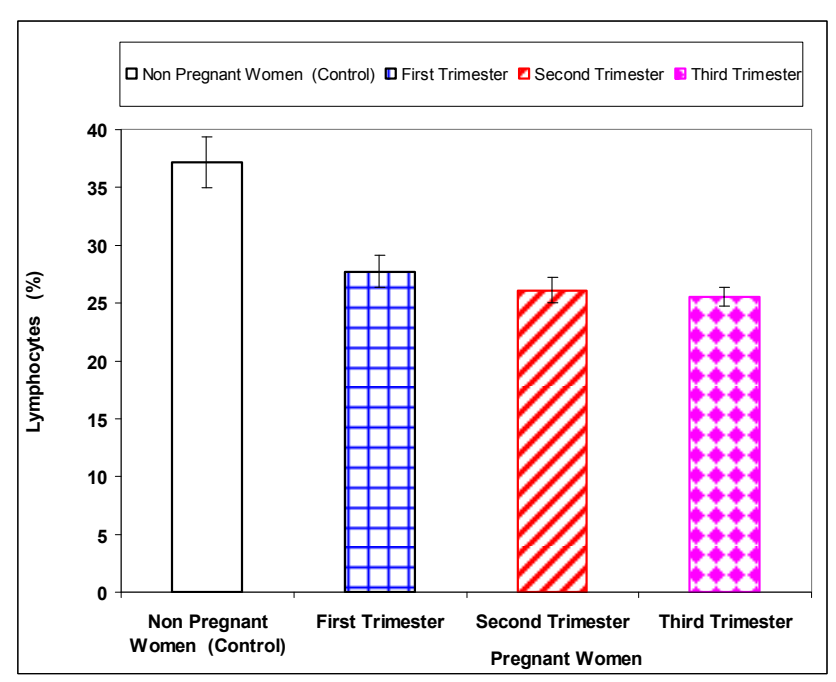

Figure 9. Lymphocytes percentage (\%) in non pregnant and Pregnant women at the first, second and third trimesters.

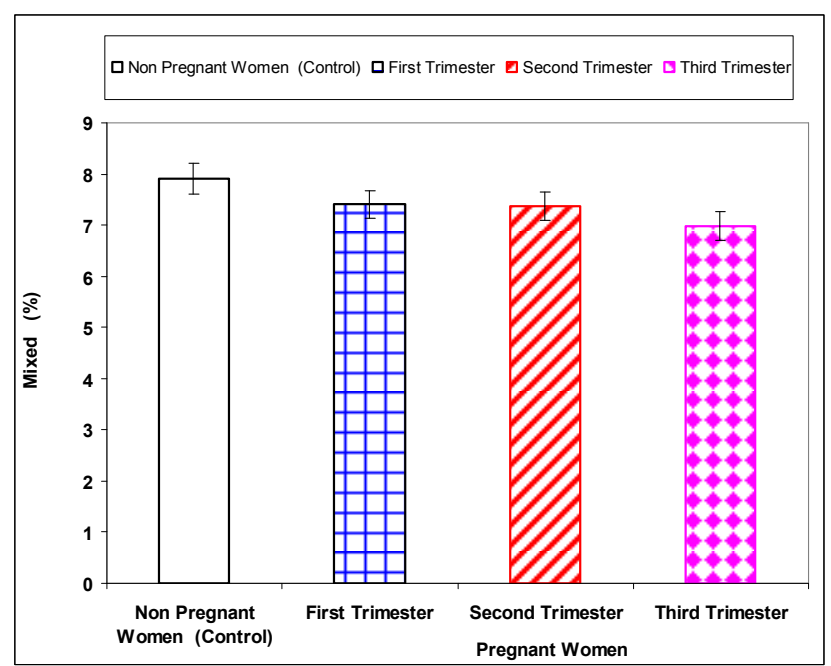

Figure 10. Mixed percentage (\%) in non pregnant and pregnant women at the first, second and third trimesters.

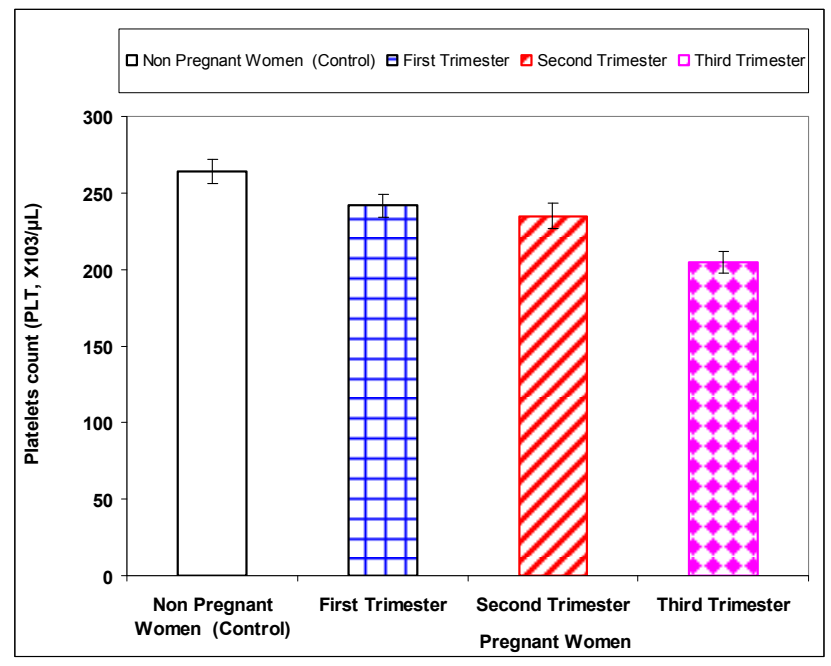

Figure 11. Platelets count in non pregnant and pregnant women at the first, second and third trimesters.

\section{Discussion}

The mean age of pregnant women was 30 years $\pm 5.8 \mathrm{SD}$ (ranged from $18-45$ years). There were $48.4 \%$ of pregnant women between $21-30$ years old, $40.8 \%$ were with age between $31-40$ years, $5.8 \%$ were with age $>40$ years, and $5 \%$ were with age $<20$ years. Similarly, the ages of the pregnant women in Derna city, Libya were ranged from 15 to 48 years with a mean age of $30.3 \pm 6.2$ years [13]. Akinbami et al., [5] reported that the mean age of pregnant women in Lagos, Nigeria was $30.52 \pm 4.6$ years (range: $20-46$ years old). But, the mean age of pregnant women in Northwestern Ethiopia was 26.13 year \pm 4.55 year standard deviation. The minimum and maximum age of the study participants were 17 and 45 years, respectively [14]. Melku and Agmas [14], recorded that $38.2 \%$ of pregnant women were between $26-30$ years old, $37.4 \%$ were with age between $20-25$ years, $12.3 \%$ were with age $<20$ years, $8.6 \%$ were with age between $31-35$ years, and $3 \%$ were with age $>35$.

The present study showed that the most prevalent blood group in pregnant women was group $\mathrm{O}$, followed by blood group $\mathrm{A}$, blood group $\mathrm{B}$, and blood group $\mathrm{AB}$. The $\mathrm{ABO}$ blood group distribution varies in different geographical and ethnic groups. Nevertheless, in almost all, O blood group is the predominant followed by $\mathrm{A}$ blood group while $\mathrm{AB}$ is the rarest which is in line with the finding of this study $[15,16]$. Comparable results were reported in Pakistan where blood group B is rather the most common phenotype [17]. Blood group A was the second most abundant phenotype in this study (28\%), which was in contrast with a study in Nepal where phenotype $\mathrm{A}$ is the predominant phenotype [18].

In the present study $15.8 \%$ of the pregnant women were lack $\mathrm{Rh}$ antigen in their blood. This result is similar with study conducted in Ethiopia. The study conducted in Southwest Ethiopia where 955 men and 1010 women were included, the $\mathrm{Rh}$ negativity was $14.8 \%$ [15]. Rh (D) distribution also varies worldwide. In contrast, Rh (D) negative blood group is documented as $5.5 \%$ in south India [19], $5 \%$ in Nairobi [20], $4.8 \%$ in Nigeria [21], $7.7 \%$ in Rawalpindi [17], 8.8\% in North Ethiopia [16].

In the present study $67.5 \%$ of pregnant women were employed, and $32.5 \%$ were housewives. $35.8 \%$ of pregnant women were teachers, $15 \%$ worked in hospitals, $8.3 \%$ were office workers, 5.8 were university staff members and $2.5 \%$ were Engineers. In Iran, Khojasteh et al., [22], found that $46.7 \%$ of pregnant women were employed, and $53.3 \%$ were housewives. In terms of type of employment, $38.7 \%$ were teachers, $18.9 \%$ worked in hospitals, and $42.5 \%$ were office workers.

Haematological abnormalities, especially anemia, may have adverse impact on pregnancy outcome and in most developing countries makes an important contribution to maternal mortality and morbidity [2]. Significant effort is therefore given to monitoring and responding to hematological parameters [2, 23].

The results of the present study showed a highly significance decrease in $\mathrm{Hb}, \mathrm{Hct}, \mathrm{MCH}, \mathrm{MCHC}$, 
lymphocytes\%, RBCs and blood platelets count and significant decrease in $\mathrm{MCV}$ in pregnant women compared with non pregnant women. On the other hand, highly significance increased in WBCs count, and neutrophils \% of pregnant women compared with non pregnant women. In our study a progressive decline in $\mathrm{Hb}$ concentration from the first to third trimester. Similar results were demonsterated by Akinbami et al., [5], who found that a progressive decline in $\mathrm{Hb}$ concentration from the first to the third trimester. These findings corroborate those of a similar study undertaken in Ibadan, south-western Nigeria, by Akingbola et al [24] in 2006, which reported exactly the same pattern. The progressive decline in $\mathrm{Hb}$ concentration from the first to third trimester may be due to an increased demand for iron as pregnancy progresses [5]. More iron is required to meet the expansion of maternal $\mathrm{Hb}$ mass and the needs of fetal growth. The additional progesterone and estrogen that are secreted by the placenta during pregnancy cause a release of renin from the kidneys [5]. During pregnancy, plasma renin activity tends to increase and atrial natriuretic peptide levels tend to reduce, though slightly. This suggests that, in pregnant state, the elevation in plasma volume is in response to an under filled vascular system resulting from systemic vasodilatation and increase in vascular capacitance, rather than actual blood volume expansion, which would produce the opposite hormonal profile instead (i.e., low plasma renin and elevated atrial natriuretic peptide levels) $[25,26]$. During pregnancy, the total blood volume increases by about 1.5 liters, mainly to supply the demands of the new vascular bed and to compensate for blood loss occurring at delivery [27]. The increase in plasma volume is relatively greater than the increase in red cell mass, which results in a fall in maternal $\mathrm{Hb}$, hence the physiological anemia that occurs in pregnancy [5]. The drop in hemoglobin is typically by $1-2 \mathrm{~g} / \mathrm{dL}$ by the late second trimester and stabilizes thereafter in the third trimester, when there is a reduction in maternal plasma volume owing to an increase in levels of atrial natriuretic peptide [3].

The present study revealed that a highly significant decreased in haematocrite values in the first, second and third trimesters compared to non pregnant women. Similar result was observed by Wulsa et al., [28], who reported that haematocrite values showed statistically significant decrease in pregnant women of $1^{\text {st }}$ Trimester, $2^{\text {nd }}$ trimester and $3^{\text {rd }}$ trimester when compared to controls with $(p<0.01)$. This decrease in haematocrite values could be due to marked increase in plasma volume associated with normal pregnancy causing dilution of many circulating factors and cells resulting in physiological anemia [29-31].

Data in the present study showed that a significant decreased in mean corpuscular volume (MCV) in the second trimester, and non significant changes in the first and third trimesters compared to non pregnant women. Akinbami et al., [5] reported that MCV declined from the first to third trimesters. These findings may be a reflection of iron deficiency anemia [5]. MCV does not change significantly during pregnancy and a hemoglobin concentration $\backslash 9.5 \mathrm{~g} / \mathrm{dL}$ in association with a mean corpuscular volume $84 \mathrm{fl}$ probably indicates co-existent iron deficiency or some other pathology [32].

The values of $\mathrm{MCH}$ were highly significant decreased in the second and third trimester, and $\mathrm{MCHC}$ were significantly decreased in the first trimester compared to non pregnant women. In contrast, Akinbami et al., [5] reported that $\mathrm{MCH}$ remained relatively stable through all trimesters. MCHC was stable in the first and second trimester but dropped in the third. These findings may be a reflection of iron deficiency anemia [5].

In the present study, WBC count was highly significant increased from the first to the third trimester. The increase observed in WBC count from the first to third trimester in this study is consistent with the findings of Akinbami et al., [5], Onwukeme and Uguru [11], and Akingbola et al., [24]. The increase is primarily due to an increase in neutrophils and may represent a response to stress due to redistribution of the WBCs between the marginal and circulating pools [5, 33]. Pain, nausea, vomiting, and anxiety have been reported to cause leukocytosis in the absence of infection [5, 34]. A rising WBC count in pregnancy is not a reliable indicator of infection in subclinical chorioamnionitis; rather, clinical methods of detection such as maternal pyrexia, offensive vaginal discharge, and fetal tachycardia are better indicators, especially of preterm labor and membrane rupture [5].

The data obtained in the present study revealed that neutrophils \% were highly significant increased in the first, second, and third trimesters as compared with non pregnant women. Similarly, the neutrophil count begins to increase in the second month of pregnancy and plateaus in the second or third trimester, at which time the total white blood cell counts range from 9000 to 15,000 cells/microL [35]. Neutrophils are the major type of leucocytes on differential counts [36, 37]. This is likely due to impaired neutrophilic apoptosis in pregnancy [36]. The neutrophil cytoplasm shows toxic granulation. Neutrophil chemotaxis and phagocytic activity are depressed, especially due to inhibitory factors present in the serum of a pregnant female [38]. There is also evidence of increased oxidative metabolism in neutrophils during pregnancy. Immature forms as myelocytes and metamyelocytes may be found in the peripheral blood film of healthy women during pregnancy and do not have any pathological significance [39]. They simply indicate adequate bone marrow response to an increased drive for erythropoiesis occurring during pregnancy.

The present study demonstrated a highly significant decreased in lymphocytes \% in the first, second and third trimesters compared to non pregnant women. The present results are in agreement with those obtained by Kline et al., [40] who found a significant decreases in lymphocyte count during pregnancy through the first and second trimesters.

The present work showed that mixed percentage of leukocytes (eosinophil, basophil and monocytes) were decreased significantly in the third trimesters, and non significant changed in the first and second trimesters when compared with non pregnant women. In contrast, Kline et 
al., 2005 reported that there is an absolute monocytosis during pregnancy, especially in the first trimester, but decreases as gestation advances. Monocytes help in preventing fetal allograft rejection by infiltrating the decidual tissue (7th- 20th week of gestation) possibly, through PGE2 mediated immunosuppression [40]. Eosinophil and basophil counts, however, do not change significantly during pregnancy [41].

In the present study blood platelets count exhibited a highly significant decreased in the second and third trimesters, and a significant decreased in the first trimester compared to non pregnant women. Similar results were noticed by Akinbami et al., [5], and Akingbola et al., [24] who reported a gradual reduction in PLT count as pregnancy advanced. Also, Abbassi-Ghanavati et al., [8] reported that PLT count was slightly lower in pregnant than in non pregnant women. Due to hemodilution secondary to expansion of plasma volume, the PLT count in normal pregnancies may decrease by approximately $10 \%$, with most of this decrease occurring during the third trimester $[42,43]$, although the absolute PLT count tends to remain within the normal reference range in most patients $[9,42$, 43]. PLT counts may be lower in women with twin compared with singleton pregnancies, possibly due to greater thrombin generation [44]. The mechanisms for this are thought to be due to dilution effects and accelerated destruction of PLTs passing over the often scarred and damaged trophoblast surface of the placenta ([5, 45]. Although most cases of thrombocytopenia in pregnancy are mild, with no adverse outcome for mother or baby, occasionally a low PLT count may be part of a complex disorder with significant morbidity and be (rarely) lifethreatening [5].

\section{Conclusion}

It can be concluded that a significant changes in the haematological parameters at different trimesters of pregnancy in pregnant women. So it is essential to monitor and manage these parameters during pregnancy. Further studies should be conducted to indicate the prevalence and causes of anemia and thrombocytopenia in Libyan pregnant women.

\section{References}

[1] Mohamed A. O., Hamza K. M., Babker A. M. A. (2016). Physiological changes in some hematological and coagulation profile among Sudanese healthy pregnant women. Int. J. Med. Sci. Public Health, 5: 525-528.

[2] Purohit G., Shah T., and Harsoda J. M. (2015). Hematological profile of normal pregnant women in Western India. Sch. J. App. Med. Sci., 3 (6A): 2195-2199.

[3] Chandra S., Tripathi K., Mishra S., Amzarul M., and Vaish A. (2012). Physiological changes in hematological parameters during pregnancy. Indian J. Hematol. Blood Transfus., 28 (3): 144-146.
[4] Akinlaja O. (2016). Hematological changes in pregnancy - the preparation for intrapartum blood loss. Obstet. Gynecol. Int. J., 4 (3): 00109.

[5] Akinbami A. A., Ajibola S. O., Rabiu K. A., Adewunmi A. A., Dosunmu A. O., Adediran A., Osunkalu V. O., Osikomaiya B. I., and Ismail K. A. (2013). Hematological profile of normal pregnant women in Lagos, Nigeria. Inter. J. Women Health, 5: 227- 232.

[6] Stevens G., Finucane M., De-Regil L., Paciorek C., Flaxman S., Branca F. et al. (2013). Nutrition impact model study group (Anaemia). Global, regional, and national trends in haemoglobin concentration and prevalence of total and severe anaemia in children and pregnant and non-pregnant women for 1995-2011: A systematic analysis of populationrepresentative data. Lancet Glob Health., 1: 16-25.

[7] Jiji D. B. and Rajagopal K. (2014). A study to assess the knowledge and risk factors of anaemia among the pregnant women attending selected health care facilities in Sebha, Libya. J. Sci., 4 (1): 19-22.

[8] Abbassi-Ghanavati M., Greer L. G., and Cunningham F. G. (2006). Pregnancy and laboratory studies: a reference table for clinicians. Obstet. Gynecol., 114 (6): 1326-1331.

[9] Boehlen F., Hohlfeld P., Extermann P., Perneger T. V., and de Moerloose P. (2000). Platelet count at term pregnancy: A reappraisal of the threshold. Obstet. Gynecol., 95 (1): 29-33.

[10] Jensen J. D., Wiedmeier S. E., Henry E., Silver R. M., and Christensen R. D. (2011). Linking maternal platelet counts with neonatal platelet counts and outcomes using the data repositories of a multihospital health care system. Am. J. Perinatol., 28 (8): 597-604.

[11] Onwukeme K. E., and Uguru V. E. (1990). Haematological values in pregnancy in Jos. W Afr. J. Med., 9 (2): 70-75.

[12] Patel PA, Patel SP, Shah JV, et al. (2012). Frequency and distribution of blood groups in blood donors in western Ahmadabad - A hospital based study. National J Med Res, 2 (2): 202-206.

[13] Elzahaf R. A., and Omar M. (2016). Prevalence of anaemia among pregnant women in Derna city, Libya. Int. J. Community Med. Public Health, 3 (7): 1915-1920.

[14] Melku M., and Agmas A. (2015). Maternal anemia during pregnancy in Bahirdar Town, Northwestern Ethiopia: A facility-based retrospective study. Appl. Med. Res., 1 (1): 2-7.

[15] Haileamlak A., Muluneh A. T., Alemseged F, et al. (2012). Hematoimmunological Profile At Gilgel Gibe Field Research Center, Southwest Ethiopia. Ethiop J. Health Sci., 22: 39-50.

[16] Alemu M., Abrha G., Bugssa G., and Tedla K. (2014). Frequency of $\mathrm{ABO}$ and $\mathrm{Rh}(\mathrm{D})$ blood groups and hemoglobin threshold among pregnant women in family guidance association, Mekelle model clinic, North Ethiopia. Inte. J. Pharm. Sci. Res., 5 (12): 892-895.

[17] Bhalti F. A., and Amin (1996). Spectrum of ABO and D blood groups of donors at Rawalpindi/ Islamabad. Pakistan J. Pathol., 7 (2): 26-28.

[18] Pramanik T., and Pramanik S. (2000). Distribution of ABO and Rh blood groups in Nepalese students: a report. Eastern Mediterranean Health J., 6 (1): 156-158. 
[19] Chavhan A., Pawar S., and Baig M. M. (2010). Allelic frequency of $\mathrm{ABO}$ and $\mathrm{Rh} \mathrm{D}$ blood group among the Banjara backward caste of Yavatmal district, Maharashtra, India. Nature Precedings: hdl:10101/npre.2010.5482.1.

[20] Kibaya R. S., Bautista C. T., Sawe F. K., et al.(2008). Reference ranges for the clinical laboratory derived from a rural population in Kericho, Kenya. PLoS One, 3 (10): 3327. DOI: 10.1371 journal.pone.0003327.

[21] Omotade O. O., Adeyemo A. A, Kayode CM, et al.(1999). Gene frequencies of $\mathrm{ABO}$ and $\mathrm{Rh}(\mathrm{D})$ blood group alleles in a healthy infant population in Ibadan, Nigeria. West Afr. J. Med., 18: 294-297.

[22] Khojasteh F., Arbabisarjou A., Boryri T., Safarzadeh A., and Pourkahkhaei M. (2016). The relationship between maternal employment status and pregnancy outcomes. Global J. Health Sci., 8 (9): 37-43.

[23] Shah A., Patel N. D., and Shah M. H. (2012). Hematological parameters in anemic pregnant women attending the antenatal clinic of rural teaching hospital. Innovative J. Med. Health Sc., 2 (5): 70-73.

[24] Akingbola T., Adewole I. F., Adesina O. A., Afolabi K. A., Fehintola F. A., Bamgboye E. A., Aken'ova Y. A., Shokunbi W. A., Anwo J. A., and Nwegbu M. M. (2006). Haematological Profile of healthy pregnant women in Ibadan, south western Nigeria. J. Obstet. Gynaecol., 26 (8): 763- 769.

[25] Barriga C., Rodriguez A. B., and Orega E. (1994). Increased phagocytic activity of polymorphonuclear leucocytes during pregnancy. Eur. J. Obstet. Gynecol. Reprod. Biol., 57 (1): 43-46.

[26] Ajzenberg N., Dreyfus M., Kaplan C., Yvart J., Weill B., and Tchernia G. (1998). Pregnancy-associated thrombocytopenia revisited: assessment and follow-up of 50 cases. Blood, 92 (12): 4573-4580.

[27] Ramsay M. (2010). Normal hematological changes during pregnancy and the puerperium. In: Pavord S, Hunt B (eds) The obstetric hematology manual. Cambridge University Press, Cambridge, pp: 1-11.

[28] Wulsa N., Soren G., Pathapati R. M., and Buchineni M.(2015). Cardiopulmonary and hematological parameters in pregnancy. IAIM., 2 (12): 1-6.

[29] Salawu L., and Durosinmi M. (2000). Erythrocyte rate and plasma viscosity in health and disease. J. National Association Resid. Doctors Nigeria, 10 (1): 11-3.

[30] Imoru M., and Emeribe A. (2009). Haemorrheologic and fibrinolytic activities in pregnant women: Influence of gestational age and parity. African J Biotechnol., 8 (23): 6641-6644.

[31] Oke O. T., Awofadeju S. O., and Oyedeji S. O. (2011). Haemorheological profiles in different trimesters among pregnant women in South West Nigeria. Pak. J. Physiol., 7 (2): 17-19.
[32] Crocker I. P., Baker P. N., and Fletcher J. (2000). Neutrophil function in pregnancy and rheumatoid arthritis. Ann. Rheumat. Dis. 59: 555-564.

[33] Fleming A. F. (1975). Hematological changes in pregnancy. Clin. Obstet. Gynecol. 2: 269-283.

[34] Milhorat A. T., Small S. M., and Diethelm O. (1942). Leukocytosis during various emotional states. Arch Neurol. Psych., 47 (5): 779-792.

[35] Kuvin S. F., and Brecher G. (1962). Differential neutrophil counts in pregnancy. N. Engl. J. Med., 266: 877-878.

[36] Gatti L., Tinconi P. M., Guarneri D., Bertuijessi C., Ossola M. W., Bosco P., Gianotti G. (1994). Hemostatic parameters and platelet activation by flow-cytometry in normal pregnancy: A longitudinal study. Internat J. Clin. Lab. Res., 24 (4): $217-$ 219.

[37] Konijnenberg A., Stokkers E., and van der Post J. (1997). Extensive platelet activation in preeclampsia compared with normal pregnancy: Enhanced expression of cell adhesion molecules. Am. J. Obstet. Gynecol., 176 (2): 461469.

[38] Jessica M., Badger F., Hseih C. C., Troisi R., Lagiou P., and Polischman N. (2007). Plasma volume expansion in pregnancy: Implications for biomarkers in population studies. Cancer Epidemiol. Biomarkers 16: 1720 - 1723.

[39] Karalis L., Nadan S., and Yemen E. A. (2005). Platelet activation in pregnancy induced hypertension. Thromb Res., 116 (5): $377-383$

[40] Kline A. J., Williams G. W., and Hernandez-Nino J. (2005). D-Dimer concentration in normal pregnancy: new diagnostic thresholds are needed. Clin. Chem., 51 (5): 825829 .

[41] Edlestam G., Lowbeer C., Kral G. et al (2001). New reference values for routine blood samples and human neutrophilic lipocalin during third trimester pregnancy. Scand J. Clin. Lab. Inv., 61: 583-592.

[42] Ballem P. J. (1988). Hematological problems of pregnancy. Can. Fam. Physician., 34: 2531-2537.

[43] McCrae KR. (2003). Thrombocytopenia in pregnancy: differential diagnosis, pathogenesis and management. Blood Rev., 17: 7-14.

[44] Tsunoda T, Ohkuchi A, Izumi A, et al. (2002). Antithrombin III activity and platelet count are more likely to decrease in twin pregnancies than in singleton pregnancies. Acta Obstet. Gynecol. Scand., 81 (9): 840-845.

[45] Fay R. A., Hughes A. O., Farron N. T. (1983). Platelets in pregnancy: hyperdestruction in pregnancy. Obstet. Gynecol., 61 (2): 238-240. 